\title{
STUDY OF PARAMETERS OF ELEMENTS OF A FELLING HEAD FOR LIFTING AND MOVING TREES FOR THE PURPOSE OF CLEARING AGRICULTURAL LANDS AND AGROFORESTRY
}

\author{
Denis Mihailovich Lastochkin* \\ Volga State University of Technology, Russian Federation \\ Evgeny Mihailovich Onuchin \\ Volga State University of Technology, Russian Federation \\ Andrey Andreevich Medyakov \\ Volga State University of Technology, Russian Federation \\ Denis Vladimirovich Kostromin \\ Volga State University of Technology, Russian Federation \\ Aleksey Petrovich Ostashenkov \\ Volga State University of Technology, Russian Federation
}

The purpose of this article is the theoretical justification of parameters of the felling head elements and experimental studies of its the work technique on the basis of the tractor of the drawbar category 0.6-1.4. The essence of theoretical study is to determine parameters of the mounted felling head for cutting and vertical holding of a tree of a diameter of 10 to $22 \mathrm{~cm}$, taking into account the optimal working zone of the tilt mechanism. Experimental study was carried out on a prototype of a one-grip felling machine (OGFM) (based on the T-25 tractor) with the mounted felling head. In the process of carrying out field studies, technological performance parameters of the OGFM for low-capacity logging and the pressure in the hydraulic system of the felling head were studied under various operating conditions.

Key words: Felling head, Tilt mechanism, Recultivation of old agricultural lands

\section{INTRODUCTION}

Russia has the world's largest forest resources and a huge potential in the field of forest bioenergetics. The development of bioenergetics helps create jobsites, improve the environmental situation, and reduce the dependence of individual regions on fossil energy sources.

During the development of the bioenergetics industry, the need for additional sources of wood raw materials will increase. Wood obtained from recultivation of old agricultural lands can be considered as one of these sources of raw materials.

Biofuel development of old agricultural lands will allow farmers to ensure the recultivation of old fields and provide additional income.

Overgrown agricultural lands have heterogeneity in the rock composition, in the density of overgrowth and the volume of trees. This significantly distinguishes them from fast-growing plantations, which affects the way biomass is harvested.

Great interest in the field of bioenergetics is represented by foreign experience, first of all in the Scandinavian countries, where the production of energy from wood nowadays plays an important role in the life of society. But it should be taken into account that the differences in the production and economic conditions do not allow using the accumulated experience of foreign countries in the field of forest bioenergetics directly in Russia, without appropriate adaptation [07, 16].

Existing methods of harvesting small-sized trees based on machine methods of work can be carried out using manipulators and machines using rear and frontal attached rig of a tractor. The obtained experience of using small-sized felling machines of the front type in the development of the forest fund is insufficient. Therefore, taking 
into account the specifics and operating conditions of such machines associated with the possibility of moving cut trees in a vertical position under the canopy of the forest, it is important to conduct studies to evaluate the productivity of a small-sized felling machine.

\section{ANALYSIS OF THE BIOENERGY POTENTIAL}

According to the data of the state statistical reporting [17] of January 1, 2015, the area of the land fund of the Russian Federation was 1709.9 million hectares, the largest categories of which were forest lands with an area of 1,122.6 million hectares $(65,7 \%)$ and lands for agricultural purposes with an area of 385.5 million hectares $(22.5 \%)$. The total area of agricultural lands in the area of lands for agricultural purposes was 196.2 million hectares (50.9\%). Agricultural lands include arable lands, hayfields, pastures, lands occupied by perennial plantations (orchards, vineyards and other perennial crops), and old field.

Economic and social reforms of the 1990s led to a sharp reduction in collective and state farms. This led to the fact that many agricultural lands were transferred into the old fields and not farmed (because of the reduction of arable lands and the reduction in the number of livestock) [09]. The percentage of old fields in Russia's agricultural lands is $2.2 \%$ or 4.9 million hectares [17]. The long unclaimedness of the old fields leads to the fact that in 20-25 years they begin to grow shrubs, and young growth is formed on the bordering with woodland lots [02]. When reclaiming old agricultural lands, it is necessary to clear significant areas not only from bushes but also from young trees whose diameter reaches $22 \mathrm{~cm}$ [02]. Thus, the use of young trees and shrubs grown on old lands as an energy biomass is of great practical and economic importance.

If the biomass in the form of wood chips is taken as the final product of the harvest of small-sized trees, short rotation coppices (SRC) are analogous to overgrown agricultural lands with thinsized trees. In many European countries, the cultivation of SRC is a widespread agricultural practice [16]. Despite 30 years of experience in the practical use of artificial bioenergetic plantations in European countries, there is no knowledge of harvesting small-sized timber grown on old farm lands. Machines and mechanisms used in logging in fast-growing forest plantations can not be fully used without adaptation in naturally grown agricultural lands. This is due to the heterogeneity of tree growth in density and volume. Machines used in conventional tree harvesting technologies have large capacities and capabilities that can not be fully used when working in low-volume forest areas [10].

\section{ANALYSIS OF HARVESTING EQUIPMENT}

Since the estimated diameter of the harvesting trees is up to $22 \mathrm{~cm}$, conventional technologies and machines used for harvesting bioenergetic wood can not be used in full [06]. In this case, it is necessary to consider classical logging machines and their technologies.

The existing technologies for harvesting trees for their subsequent grinding can be divided into 2 groups:

1) Tree-length logging. Trees are harvested in the form of tree-length material and skidded to the site of bucking and grinding.

2) Assortment logging. The trees are processed on the site in order to be sorted and taken to the stationary grinding station.

Each of the technologies for harvesting and processing small-sized trees has been repeatedly studied and there are a sufficient number of publications $[01,04,08,10,12,13,15,18]$. In existing works, the advantages and disadvantages, costs and performance of existing machines and technologies were analyzed. Analysis of the technological chain of accelerated forest growing and subsequent harvesting and processing shows that the costs of harvesting equipment remain the most significant impediment in the general cycle of logging of thin-wood to obtain energy biomass.

Analysis of existing harvesting machines and shredders shows that they have a weight of 11 to 14 tons, and the combine for cutting bushes and subsequent grinding on average weighs 15 tons [06]. These machines are effective when working on the area of more than 300 hectares [11].

Another group of equipment and technologies is based on the use of agricultural tractors up with additional equipment on the front or rear hinge [05]. Most of the known shredding equipment work with fallen trees. Worthy of attention equipment are those for simultaneous cutting and chopping of trees directly on the felling area $[03,20,21]$. But there are also small-sized fell- 
chines with an attached harvester head or felling head [14]. The problem of a mounted unit is that the more complex the unit is the more moving parts it has. Thus as for logging machines, the movement of all their mechanisms is provided by various hydraulic motors and hydraulic cylinders, which in combination with the hydraulic pumps, hydraulic tank, and hydraulic lines increases the mass of additional equipment from 1 to 4 tons. Analyzing the existing solutions we can conclude that there are some limitations for harvesting machines connected with the thickness of the cut plant of $6 \mathrm{~cm}$, which greatly limits the range of use of such machines.

Based on the analysis of existing equipment for harvesting bioenergetics wood, the following conclusions can be drawn:

- High cost of harvesting on the lands of the European part;

- There are no universal harvesting machines suitable for all types and sizes of the forest stand and operating under different conditions.

\section{MATERIALS AND METHODS}

\section{The mounted felling head development}

Due to the insufficient technical development of machines and equipment for harvesting smallsized trees in the reclamation of old agricultural lands, the experimental design project was initiated at the Volga State University of Technology, Yoshkar-Ola, Russia. The project included the development and designing of a mobile mounted felling head for lifting and moving trees with a diameter of 10 to $22 \mathrm{~cm}$.

The developed felling head has a weight of 300 $\mathrm{kg}$ and is mounted on the rear three-point hitch of a tractor of the drawbar category of $0.6-1.4$ [19]. The height of the felling head from the circular saw to the upper seat is $1 \mathrm{~m}$. The length of the jib to the cardan joint is $0.7 \mathrm{~m}$. The basic length of the hydraulic cylinders of the tilt mechanism is $0.55 \mathrm{~m}$ with the working stroke of the piston of $0.4 \mathrm{~m}$.

Mounting of the felling head took place without making changes to the design of the tractor. Also, to ensure the technology of transportation of the vertical tree from the canopy of the forest, it was ensure to securely clamp and hold the cut tree.

The following requirements were laid down in the basis of the technical assignment for the design of the felling head:

- Reliable and simple construction;

- Effective cutting of trees of different diameters;

- Reliable holding of one tree while the tractor is moving.

The basic design of the developed felling head is presented in Figure 1.

For implementation the simple and reliable design, the number of moving parts has been reduced. The main moving elements were the circular saw blade (disk saw), the wood clamping lever and the felling head tilt mechanism.

The operation of the OGFM is as follows. The operator selects the marked tree and directs the felling head on it. The machine moves and deeps the rotating circular saw into the trunk of the tree (cutting the tree). The clamping lever presses the tree against the beam and breaks it away from the stump. The bottom of the tree rests on the footing. After that the felling head with the tree rises in the transportation position and the machine takes the vertical tree to the place of packing.

In the process of performing technological operations, the loading of the hydraulic system of the tilt mechanism of the felling head is of particular interest.

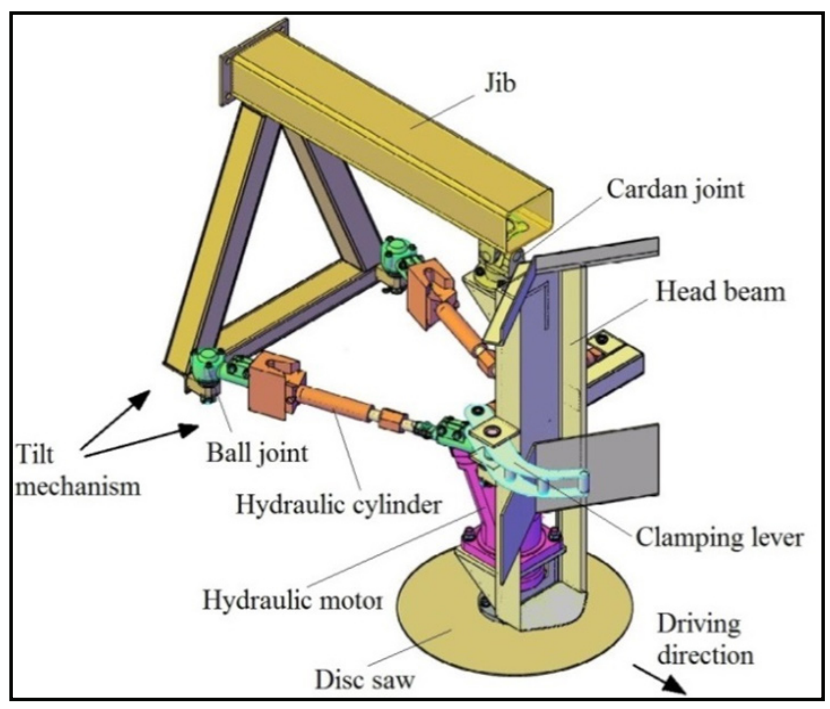

Figure 1: Design of a felling head for lifting and moving trees 


\section{THEORETICAL STUDIES OF THE STRUCTURE OF THE TILT MECHANISM}

A worthy of attention unit of the proposed design of the felling head is a tilt mechanism consisting of two hydraulic cylinders whose rods are brought together on a felling head beam, and the ends of the cylinders are apart on a sub frame. This arrangement of the hydraulic cylinders allows the felling head to be deflected both in the longitudinal and transverse planes with the minimum overall dimensions of the tilt mechanism.

The main operational characteristic of the tilt mechanism is its zone of action. The zone of action of the tilt mechanism is part of the working volume, in which the lower point $(\mathrm{Mn})$ of the felling head moves relative to the upper point (O) of the suspension. The contour of the zone of action and its area (volume) are completely determined by the kinematic parameters of the tilt mechanism, such as the main kinematic chain (the number of movable elements and the ways of their coupling), and also by the magnitude and the ratio of the length of its elements, the setting angles between them and the angles of their relative rotation.

To construct the working zone of the tilt mechanism of the felling head, its design model was proposed (Figure 2).

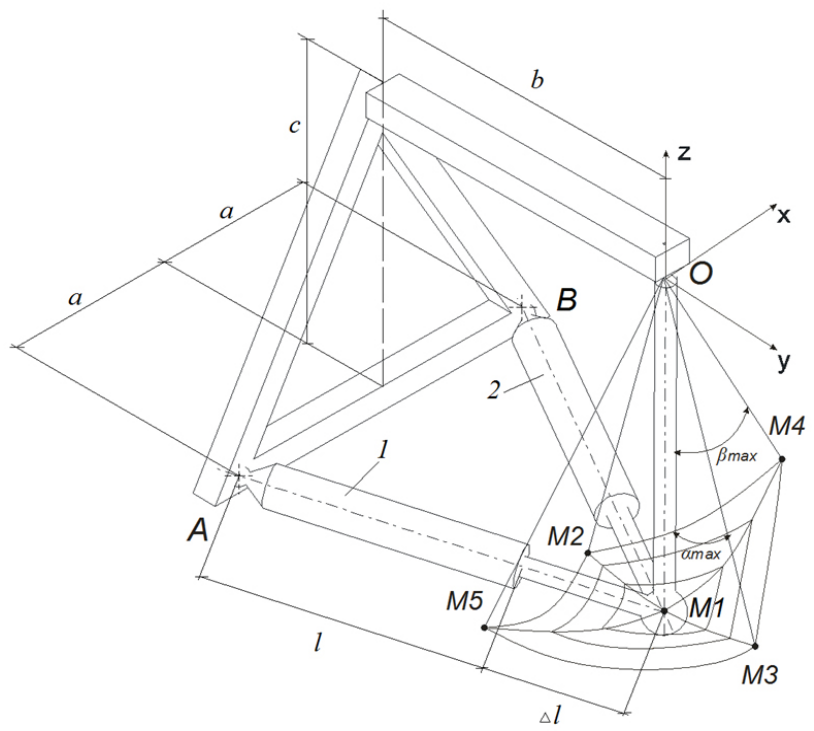

Figure 2: The design model of the tilt mechanism of the felling head and working zone of action of the tilt mechanism
The following assumptions and notations were adopted: the length of both hydraulic cylinders and the stroke of the rod are the same; $I_{0}$ is the minimum length of hydraulic cylinder (when the rod is retracted); $\Delta /$ is the stroke of the rod; $I_{0}+\Delta I_{\max }$ is the maximum length of the cylinder (when the rod is extended); $\alpha$ is the angle of deflection of the felling head beam in the longitudinal plane (Oyz); $\beta$ is the angle of deflection of the felling head beam in the transverse plane(Oxz); $M_{n}$ is the driven point of the felling head pillar.

The coupling equations of the two-rod structure with the driven link in the generalized coordinate system Oxyz have the following form:

$$
\sum_{j=1}^{3}\left(x_{j}-a_{i l}\right)=r_{i}^{2}
$$

Where, $a_{i j}$ is the $j$-th coordinate of the attachment point on the base of the $i$-th cylinder; $r$ is the current value of the cylinder length; $x_{j}$ is the required coordinates of the "vertex" of the point of attachment of the hydraulic cylinders; $i=j=1 ; 2$.

For an asymmetric mechanism, taking into account the notations in Figure 2, the coupling equation has the following form:

$$
\begin{aligned}
& x^{2}+y^{2}+z^{2}=h^{2} ; \\
& (x+l)^{2}+\left(y-a_{1}\right)^{2}+\left(z+h_{1}\right)^{2}=\left(l_{0}+\Delta l_{1}\right)^{2} \\
& (x+l)^{2}+\left(y+a_{2}\right)^{2}+\left(z+h_{1}\right)^{2}=\left(l_{0}+\Delta l_{2}\right)^{2}
\end{aligned}
$$

The result of solving this unconventional system of equations (generalized coordinates of the mechanism) will, in essence, be the equations of motion of the driven point of the tilt mechanism as a function of the current values of the length of the hydraulic cylinders.

In any geometric values of the tilt mechanism, the action zone is formed when the point Mn moves inside the zone M2-M4-M3-M5. At point M1, the felling head beam is in the vertical position along the $\mathrm{OZ}$ axis. Points M2 ... M5 denote the final position of the point Mn when the length of the hydraulic cylinders changes from the minimum length $\left(I_{0}\right)$ to the maximum length $\left(I_{0}+\Delta l\right)$.

The combination of the extreme values of the length of the hydraulic cylinders and the corresponding positions of the felling head and the point $M n$ are shown in Table 1. 
Table 1: Combination of extreme values of the length of the hydraulic cylinders and the corresponding positions of the mechanism

\begin{tabular}{|c|c|c|c|c|c|}
\hline $\begin{array}{l}\text { Length of hydraulic } \\
\text { cylinder }\end{array}$ & Position of the head beam & $\begin{array}{l}\text { Direction } \\
\text { of axes }\end{array}$ & $\begin{array}{c}\text { Extreme } \\
\text { point }\end{array}$ & Angle $\alpha$ & Angle $\beta$ \\
\hline$I_{1}=I_{2}=I_{0}+\Delta I_{\min }$ & $\begin{array}{l}\text { Initial position of the } \\
\text { mechanism }\end{array}$ & $\mathrm{Oz}$ & $M_{1}$ & $\alpha=0$ & $\beta=0$ \\
\hline$I_{1}=I_{2}=I_{0}$ & $\begin{array}{c}\text { The extreme 'backward' Žposition } \\
\text { (the rods of all hydraulic cylinders } \\
\text { are retracted) }\end{array}$ & $-O y$ & $M_{2}$ & $\alpha=-\alpha_{\max }$ & $\beta=0$ \\
\hline$I_{1}=I_{2}=I_{0}+\Delta I_{\text {max }}$ & $\begin{array}{l}\text { The extreme 'forward' position } \\
\text { (the rods of all hydraulic } \\
\text { cylinders are extended) }\end{array}$ & Oy & $M_{3}$ & $\alpha=\alpha_{\max }$ & $\beta=0$ \\
\hline$I_{2}=I_{0} ; I_{1}=I_{0}+\Delta I_{\max }$ & \multirow{2}{*}{$\begin{array}{l}\text { Limit turn on the horizon } \\
\text { (left or right) }\end{array}$} & Ox & $M_{4}$ & $\alpha=-\alpha^{\prime} \approx 0$ & $\beta=\beta_{\max }$ \\
\hline$I_{1}=I_{0} ; I_{2}=I_{0}+\Delta I_{\max }$ & & $-0 x$ & $M_{5}$ & $\alpha=-\alpha^{\prime} \approx 0$ & $\beta==-\beta_{\text {max }}$ \\
\hline
\end{tabular}

plane Oyz, which corresponds to the synchronous use of the lengths $I_{1}$ and $I_{2}$, the coverage area is characterized by the area of flat formation with the vertices (extreme points) $M_{2} \ldots M_{3}$. If the length of the hydraulic cylinders is $I 1 \neq 12$, then the felling head beam is deployed both in the longitudinal and transverse planes. It is very important that the transition to $M_{4}$ and $M_{5}$ is accompanied not only by turning the beam in the transverse plane to $\beta$ max, but also by moving the vertex $\mathrm{Mn}$ in the longitudinal plane Oxz (Figure 2).

\section{EXPERIMENTAL STUDIES OF THE DESIGN OF THE TILT MECHANISM}

Experimental studies of loading of the tilt mechanism were carried out by holding and tilting the sample tree with a felling head.

For the experiments, we chose a sample tree (Pinus sylvestris L.) with a maximum diameter at the cut point of $22 \mathrm{~cm}$ and a height of 12 meters.

The main tasks of the experimental study of the hydraulic system of the tilt mechanism of the felling head are the following:

1) Checking the operability and stiffness of the proposed design, its adjustment and additional checking.

2) Checking reliability of operation and sufficiency of mobility (degrees of freedom of hinged joints);

3) Study of the principles of independent con- trol of parallel working hydraulic cylinders;

4) Determination of the basic parameters of the work of the felling head by measuring the pressure in the hydraulic cylinders of the tilt mechanism;

5) Study of the dynamism and stability of the system in transient regimes;

6) Development of recommendations for further improvement of the structural solutions of the support and hydraulic control elements.

During the experiment, we measured the pressure in the cavities of the hydraulic cylinders. The pressure was measured in such a way as to evaluate the kinematic capabilities of the tilt mechanism. The pressure in the cavities of hydraulic cylinders characterizes mainly the dynamism of the system and, in particular, the presence or absence of unsteady operating regimes.

The measuring equipment consisted of a multichannel light-beam oscillograph and a straingage amplifier placed in the tractor's cabin. As sensors of pressure, we used sensors MD-180 (220) which are based on the principle of rheostat transformation i.e. the slider rheostat is actuated by membrane, the intensity of which is directly proportional to the pressure in the chamber of the hydraulic cylinder.

In the course of experimental study, in addition to testing the performance of the felling head and its elements, the activation of hydraulic cylinders 
- for recording the parameters - was performed in such a way as to satisfy the following conditions: one or two cylinders were simultaneously in operation, and the kinematic capabilities and increased dynamism of the system were detected.

\section{RESULTS AND DISCUSSION}

\section{Results of the theoretical study of the design of the tilt mechanism}

A study of the design of the tilt mechanism included the varying of the length of the jib, b, (Figure 2 ) of the felling head and the divergence of the fixing points of the hydraulic cylinders, a, on the prism, and the selection of their optimum values, for which the zone of action of the tilt mechanism had the optimal shape without eversion.

The construction of the working zone of the tilt mechanism was carried out taking into account the kinematic analysis according to formulas 1 and 2 .

To study the design of the tilt mechanism, a working zone was built, which was part of the sphere (Figure 2) truncated at the points $M_{2} \ldots$ $M_{5}$. The lower part of the beam (point $\mathrm{Mn}$ ) can move along the surface of this sphere within the segments $M_{2}-M_{4}-M_{3}-M_{5}$. For the convenience of analyzing the shape of the working zone of the tilt mechanism, it was projected onto the Oxy plane and represented as a circle with elongated parts along the Ox and Oy axes. In this case, the radius of the inscribed circle should be taken as the parameter for analyzing the optimal shape of the working area.

The final results of the construction of the zone of action of the tilt mechanism in the form of a symmetrical half along the Oy axis are shown in Figure 3 . The variable values are $a$ and $b$, the constant values of parameters are $c=600 \mathrm{~mm}, h$ $=700 \mathrm{~mm}, I=550 \mathrm{~mm}, \Delta I=400 \mathrm{~mm}$ (Figure 2).

The maximum inscribed circle of the working zone of action of the tilt mechanism in the theoretical calculations was $R=102 \mathrm{~cm}$, but the optimal working zone is shown in Figure 3, c. With such dimensions of the working zone, the working tilt angles of the felling head will be as follows: 'backward' - $14^{\circ}$, 'forward' - $22^{\circ}$, "sideward" - $38^{\circ}$.

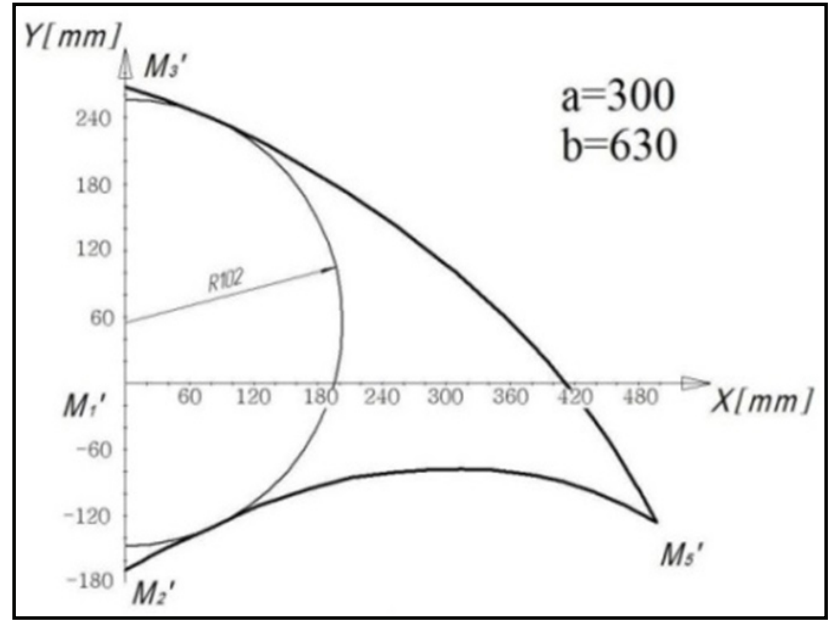

Figure 3: The working zone of the tilt mechanism (symmetrical half in the projection) and the variable values of construction

The results of an experimental study of the design of the tilt mechanism

As a result of studying the drive mechanism, it was found that the combined turn of the pillar of the felling head in the horizontal and vertical planes is more strained. The separate work of the hydraulic cylinders of the tilt mechanism causes the turn of the pillar of the felling head and is accompanied by its lifting and lowering.

When one or two hydraulic cylinders of the tilt mechanism operate, certain dynamism of the system becomes apparent. In particular, when the beam is turned and lowered due to the extension of the rod of the hydraulic cylinder from the initial position (the movement of the felling head "forward"), when the rod of the second rotary cylinder is extended, the working fluid is pumped into the piston chamber, in which the pressure Pp intensively increases (Figure 4, a).

In this work cycle, certain rise of pressure were registered in both cavities of the hydraulic cylinder, and the change in the general coordinate $\beta$ - the turning angle of the beam in the horizontal plane - is accompanied by vibration (with a stable change of another coordinate - the vertical angle $\alpha$ of the base rotation - in the range of 22 $\left.{ }^{\circ}\right)$. This feature, but to a lesser extent, also takes place in the case of the turn, lifting of the base due to the supply of liquid to the piston chamber of the hydraulic cylinder (the movement of the felling head "backward"), the turning angle of the base $\alpha$ is in the range of $14^{\circ}$ (Figure 4, b). 


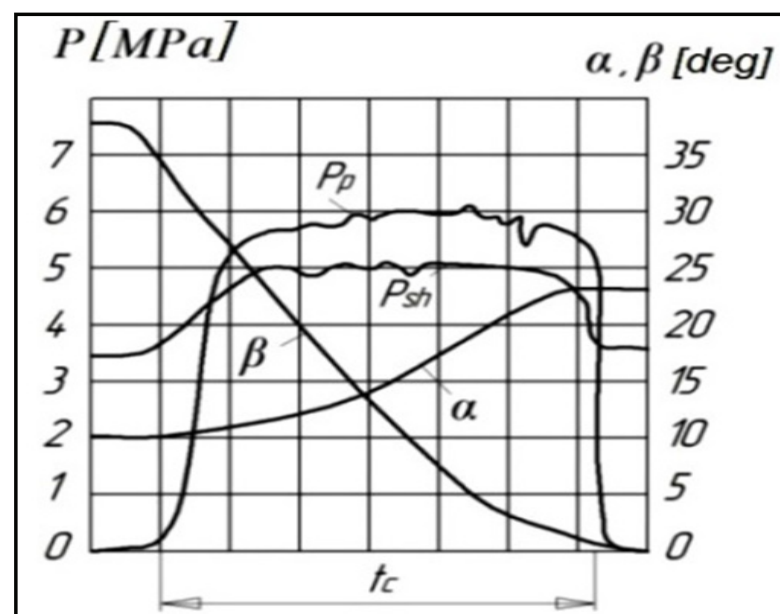

a)

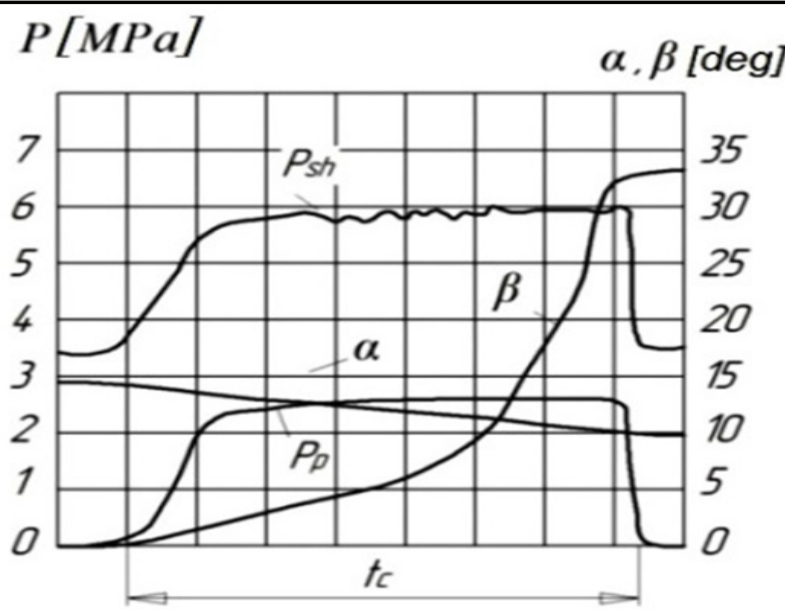

b)

Figure 4: Changing the pressure and the turning angles of the beam when the hydraulic cylinder works: the movement of the extreme lateral position: $a$ - from the extreme lateral position forward and $b$ - from the extreme lateral position backward

The most significant conclusion, which follows from the evolution of the base in space, is that the angle $\beta$ of the horizontal rotation of the base is $\pm 38^{\circ}$. The conclusion from this mode of work is the following: the stable turn of the beam is experimentally varified - without structural limitations and dynamic "perturbations" - through an angle $\alpha$ "backward" - $14^{\circ}$, "forward" - $22^{\circ}$, through an angle $\beta= \pm 38^{\circ}$ (total is $76^{\circ}$ ), which was predicted in the analytic study of the mechanism. Figure 4 shows the change of the pressure and the turning angle of the pillar during the operation of the hydraulic cylinder.
The change in the generalized coordinate $\beta$ is characterized by some vibrational processes. This is more in relief when working simultaneously with two hydraulic cylinders of the drive mechanism (Figure 5). Although the change in the generalized coordinate $\alpha$ both in the motion of the beam with a tree "forward" (a) and "backward" (b) is basically stable, the pressure in both cavities of the cylinders at a wide angle is characterized by instability.

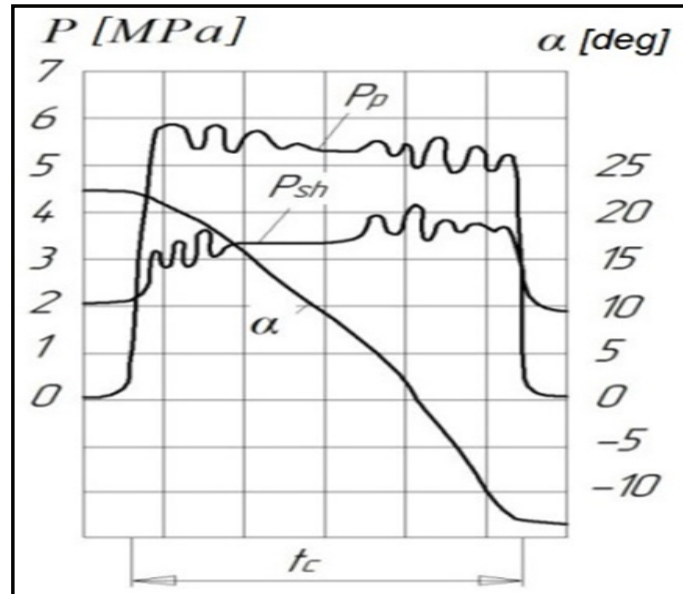

a)

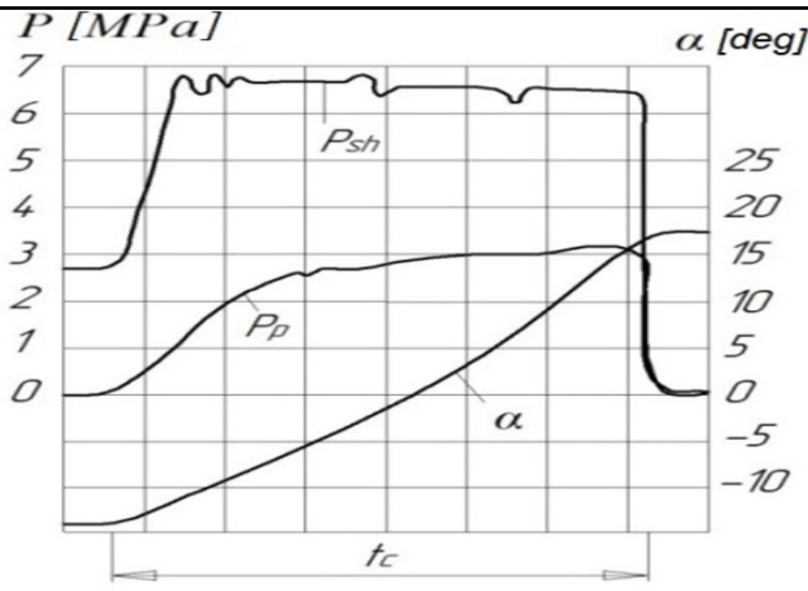

b)

Figure 5: Changing the pressure of the longitudinal angle when the felling head deviates "forward" and "backward" 
In our opinion, this is due to the fact that in the hydraulic cylinders of rotation when the working fluid is supplied to the piston (unloaded) chamber, a certain dynamic flow of the fluid appears and takes place in combination with the kinematics of the drive mechanism. This is confirmed by the more stable state of the hydraulic system when it tilts forward (Figure 5, b), since in this cycle of operation the presence of the initial pressure and the supply of the working fluid are concentrated in one piston chamber of the hydraulic cylinders.

Considering all the modes of beam turn (Figure 4 and Figure 5), we can conclude that the value of $\beta \max \pm 38^{\circ}$ is excessive; the presence of certain instability in the rotation of the beam and the indicated kinematics feature of the drive mechanism. Each angle of stable horizontal rotation of the system $\beta$ max is recommended to be limited to $25^{\circ}$ necessary for more stable control of the machine with lateral pitch.

Checking the original elements, devices and hydraulic system in the different modes as a whole indicated the following:

1) The cardan joint on the top of the beam worked stably, without jamming, did not have unregulated positions and backlashes, did not lead to jerks and bumps;

2) The shut-off and switchgears functioned clearly and stably;

3) Separate mount of rods of the hydraulic cylinders of rotation is irrational, it is advisable to ensure the attachment of these rods with each other geometrically at one point;

4) The valve-throttling shut-off devices, which eliminate pressure jumps in the hydraulic system when switching on and off, contribute to a radical reduction of dynamic loads;

5) To ensure a smooth start, movement and braking of the pins of hydraulic cylinders, to smooth the pressure rise, it is recommended to use hydraulic accumulators in the hydraulic system of the tractor.

\section{FIELD TESTS RESULTS}

Field tests were conducted on old fields at the border with the felling area of the Medvedevsky district of the Republic of Mari El (Russia). Harvesting was performed only with trees of a cut diameter of no more than $22 \mathrm{~cm}$ (Figure 6).

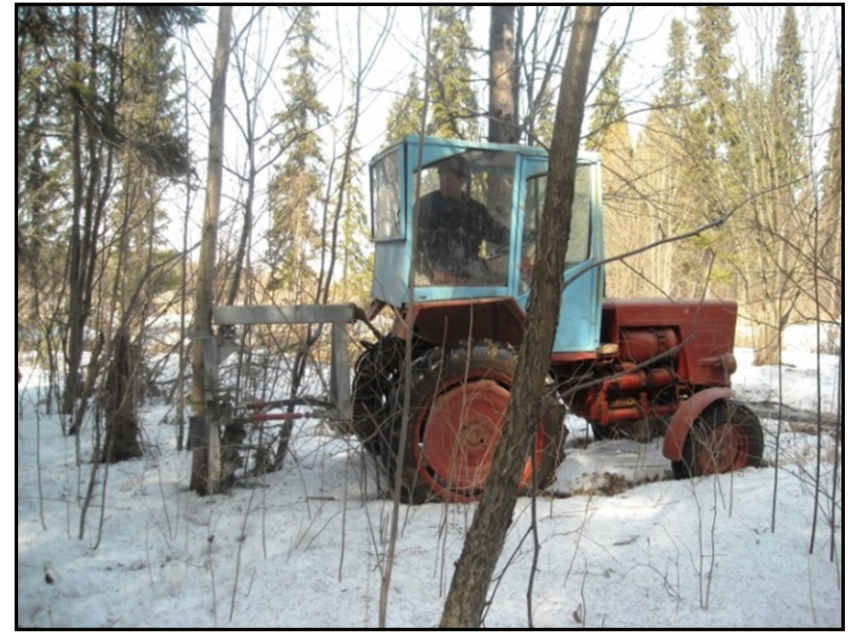

Figure 6: Operation of the OGFM

The operation sequence of the OGFM is as follows. The operator selects the marked tree and directs the felling head to it. After turning the circular saw on, the tree is cut off followed by the action of the clamping lever. The cut tree in the place of the saw cut is supported by a base plate. Then the felling head with the tree rises in the transport position and the machine takes the tree to the place of stacking.

As a result of field tests, photo-timing observations, it was found that the average cycle time of a single tree harvesting with an average transportation distance of $60 \mathrm{~m}$ was within 145-153 s. For directing the felling head and tree cutting, it was consumed from 4.5 to $11.6 \%$ of the total cycle time, for transport operations - about $86 \%$ of the total cycle time, and for stacking of trees in the package - from 1.7 to $9.3 \%$ (Figure 7 ). At the same time, the machine's productivity was $1.47-2.39 \mathrm{~m}^{3} / \mathrm{h}$.

According to the test results it was established that the machine's productivity is determined by such factors as the distance of the tree transportation, the speed of the machine, the volume of the tree, which determine the duration of the working cycle.

A comparative analysis of the cycle time consumption is performed depending on the distance of the tree transportation with the OGFM. In comparison, the most similar machine Lokomo Makeri 34T with known production values of the work [14] participated. But since the results of the compared machine were known only in the logging operations of cleaning cutting, the values of cleaning cutting at the same characteristics of the plantations were also used in the designed machine. 


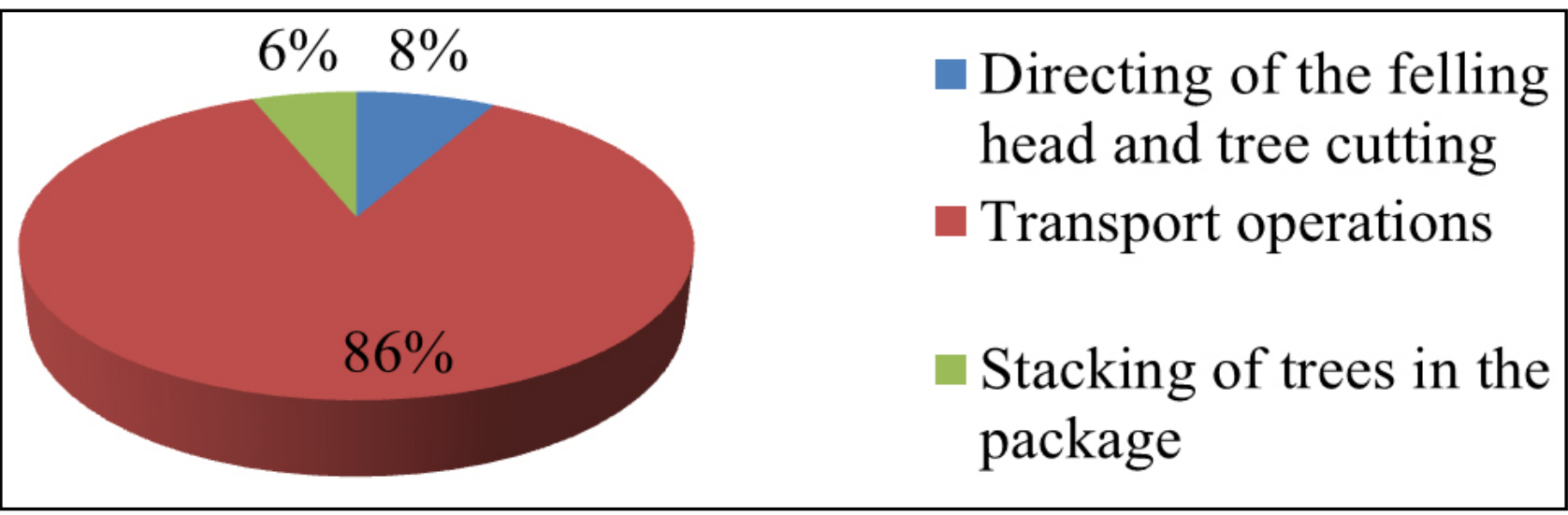

Figure 7: The average cycle time of a single tree harvesting with an average transportation distance of $60 \mathrm{~m}$

It was found that the time consumption with the transportation distance of $\mathrm{L} \geq 20 \mathrm{~m}$ by the Lokomo Makeri 34T machine was less than by the proposed felling machine. With the transportation distance of $L=60 \mathrm{~m}$, the cycle time of the OGFM was $16 \%$ larger than the Lokomo Makeri 34T. This is due to the fact that the contour area of Lokomo Makeri $34 \mathrm{~T}$ is $33 \%$ less than that of the OGFM and it maneuvers under the canopy of the forest more easily despite the fact that the range of the speeds are higher for the OGFM. However, despite a slightly shorter cycle time, the heaviness of Lokomo Makeri 34T has a negative effect on the efficiency of its use in lowvolume operations.

Analysis of the results shows that with an increase in the transportation distance up to 80 $\mathrm{m}$, the productivity is reduced by $26 \%$ compared to $L=60 \mathrm{~m}$. With an increase in the operating speeds of up to $5-6 \mathrm{~km} / \mathrm{h}$ at $\mathrm{L}=80 \mathrm{~m}$, compared to $L=60 \mathrm{~m}$ and speeds of $3-4 \mathrm{~km} / \mathrm{h}$, the productivity increases by $30 \%$.

In selective felling, an effective OGFM will be provided with the obligatory availability of a network of technological corridors with a distance between them of 40-60 m. Such organization of harvesting will ensure the use of increased speeds (up to $10 \mathrm{~km} / \mathrm{h}$ ) of traffic along the technological corridor.

The impact of the chassis of the OGFM on the surface of the technological corridor was characterized by the formation in some places of rut $8-10 \mathrm{~cm}$ in depth. It was found that machines of this type were able to process up to $85-92 \%$ of trees planned for felling at a forest stand density of up to 2-2.5 thousand per hectare. In addition to selective cleaning cutting, reclamation of overgrown fields, the OGFM are suitable for harvest- ing burnt timber, laying trails under power lines and roads, and developing felling areas with a multistoried stand.

As a result of the conducted study we can conclude the following:

- When the machine is moving with a tree, the tree trunk deviates by a value of 0.035-0.06 $\mathrm{m}$ and the corresponding reactive moment unloading the front axle of the machine by 2.9-5.1 kN depending on the intensity of the start and the parameters of the tree takes place;

- Study of the interaction of the transported tree with the growing ones, showed that when the OGFM with a tree was moving under the forest canopy, a counterweight installation was required to maintain the stability margin;

- The behavior of the dynamical system under consideration on the slope in the presence of the entire complex of influencing factors has shown that the operation of the machine on the slopes of the terrain up to $10^{\circ}$ is practically safe. On steeper slopes, it is advisable to carry out measures to ensure the stability of the machine.

\section{CONCLUSION}

Analysis of the current issue of small-sized trees harvesting has shown that using the OGFM, along with the manipulator type machines, allows to mechanize the work on reclamation of old agricultural lands, improve labor conditions, and reduce the cost of logging, depending on the specific production conditions. However, up to the present time in the Russian practice there is no experience on development and application of such a type of machines, the working process 
of which is connected with the vertical displacement of the subject of labor by the running of the machine.

Study of OGFM on the basis of a wheeled tractor of the drawbar category of 1.4 in the field conditions has shown its efficiency under the existing technical processes of cleaning cutting and small-sized trees harvesting.

When harvesting with an average tree transportation distance of $60 \mathrm{~m}$, the productivity of the proposed machine was $1.47-2.39 \mathrm{~m} 3 / \mathrm{h}$. The reserve for increasing the productivity of OGFM is the use of a system for accumulation of several trees in the felling head, shortening the working cycle time, increasing the time of the main work, and using rational technological methods specially developed for this machine.

\section{REFERENCES}

1) Abrahamson, L.P., Volk, T.A., Castellano, P., Foster, C. \& Posselius, J. (2010). Development of a harvesting system for short rotation willow \& hybrid poplar biomass crops. In: SRWCOWG MEETING, 18 Oct. 2010 Syracuse, USA.

2) Denisov, S. A., Demicheva, N.V., Egorov, V.M. (2009) Theory and practice of natural forest regeneration. http://csfm.marstu. net/elearning/vozobnovlenie/nachalo.html. 07.03.2017.

3) Döhrer, K. (1995). Harvest technique for wood fields. Die Holzzucht 49, 15-17 (in German).

4) Hartsough, B.R. \& Stokes, B.J. (1997). Short rotation forestry harvesting-systems and costs. In Proceedings of the 1997 International Energy Agency: Bioenergy task 7, activity 2.1 and activity 4.3 workshop, Melrose, (GB).

5) KWF. (2013). Think first than invest, KWFmarket overview for harvest technique for SRC. Groß-Umstadt: Kuratorium für Waldarbeit und Forsttechnik e.V., http://www. kwf-online.org/fileadmin/dokumente/Bioenergie/Dokumente/Kup-Ernter_2011.pdf. 07.03.2017.

6) Pecenka, R., Ehlert, D. \& Lenz, H. (2014). Efficient harvest lines for Short Rotation Coppices (SRC) in Agriculture and Agroforestry. Agronomy Research 12(1), 151-160.

7) Romanov, E.M., Nureeva, T.V. \& Eremin,
N.V. (2013). Artificial forest regeneration in the Middle Volga: present-day situation and problems to be solved. Vestnik of Volga State University of Technological. Series: Forest. Ecology. Nature management, 3 (19), 5-13.

8) Savoie, P., Current, D., Robert, F.S. \& Hébert, P.L. (2012). Harvest of natural shrubs with a biobaler in various environments in Québec, Ontario and Minnesota. Applied Engineering in Agriculture 28, 795-801.

9) Schiermeier, Q. (2013). Quandary over Soviet croplands. Nature 504, 342. doi:10.1038/ 504342a

10) Scholz, V., Block, A. \& Spinelli, R. (2008). Harvesting Technologies for Short Rotation Coppice - State-of-the-Art and Prospects. In Proceedings of the Agricultural Engineering 2008 Conference and Industry Exhibition, Crete, (GR).

11) Scholz, V., Eckel, H. \& Hartmann, S. (2009). Processes and costs of SRC cropping on agricultural land. In Die Landwirtschaft als Energieerzeuger. KTBL-Schrift 476, 67-80 (in German).

12) Schweier, J. \& Becker, G. (2012a). Harvesting of short rotation coppice-harvesting trials with a cut and storage system in Germany. Silva Fennica 46, 287-299.

13) Schweier, J. \& Becker, G. (2012b). New Holland forage harvester's productivity in short rotation coppice: Evaluation of field studies from a German perspective. International Journal of Forest Engineering 23, 82-88.

14) Selivjorstov, A.A., (2005). One grip harvester. Resources and Technology № 5, 98-101. http://cyberleninka.ru/article/n/odnozahvatnye-harvestery. 07.03.2017.

15) Shirnin, A.Y. \& Shirnin, Y.A. (2016). Comparison of systems of cars for extreme conditions logging. Journal of Applied Engineering Science, 14(2), 206-212. doi:10.5937/jaes14-8980

16) Shutov, I.V. \& Zhigunov, A.V. (2013) Problems of wood raw material obtaining at the vacant agricultural lands. Vestnik of Volga State University of Technological. Series: Forest. Ecology. Nature management, 4 (20), 5-17.

17) State (national) report on the status and use of land in the Russian Federation in 2014 (Moscow: Federal Service for State Registration, Cadastre and Cartography, 2015) 224. 
18) Stokes, B. \& Hartsough, B.R. (1994). Mechanization in short rotation intensive culture (SRIC) forestry. In Proceedings of 6th National Bioenergy Conference, Reno-Sparks, (US).

19) State Standard 27021-1986. Agriculturaland forestry tractors. Towing classes. Moscow, Standartov Publ., 1986. 8 p. (in Russian).

20) Stuart, W.B., Marley, D.S. \& Teel, J.B. (1983). A prototype short rotation harvester.
Proceedings of the $7^{\text {th }}$ International FPRS Industrial Wood Energy Forum '83, Nashville, (US).

21) Wieneke, F. (1993). Mower-chipper for energy plantations of poplar and willow. Landtechnik 48, 646-647, (in German).

Paper sent to revision: 17.04.2017.

Paper ready for publication: 26.06.2017. 